\title{
RHUMB-LINE SAILING BY COMPUTATION
}

\author{
Wacław Morgaś, Zdzisław Kopacz \\ Polish Naval Academy, \\ Gdynia, Poland
}

\begin{abstract}
Proposals of algorithms for solving Navigation faculty's problems regarding navigation along rhumb line (loxodrome), for officer trainees and civil students of Faculty of Navigation and Naval Weapons and for deck seamen on operational level, are presented in this paper. Proposals of calculation algorithms given in the article cover simple mathematical totting based on plane sailing (navigational) triangle and Mercator triangle (Mercator sailing). The algorithms refer to traditional methods of solving problems and they do not cover solutions applicable in automated (integrated) navigational systems.

The formulas enable to solve the tasks with a use of electronic calculator and application of traditional methods on plane and sphere, and they also take the Earth's ellipsoidal shape into consideration.
\end{abstract}

Keywords: loxodrome (rhumb-line sailing), plane (or middle latitude) sailing, Mercator triangle (Mercator sailing)

\section{Introduction}

Navigation along loxodrome, quite often named as mathematical dead reckoning, consists in calculating coordinates of the vessel's position or course and the distance she has covered by means of analytical dependencies, with no use of map.

Problems regarding the navigation along loxodrome have been covered by training programmes and examination requirements for deck seamen for a long time already, and they are presented in navigation textbooks. Stimuli for preparation of the paper have been as the following:

- $\quad$ project of Decree of Minister of Transportation, Building and Maritime Industry (MTBiGM) regarding programmes of training and examination requirements for deck seamen (MTGM, 2013), 
- bringing Central Maritime Examination Board (in Polish: Centralna Morska Komisja Egzaminacyjna) into being under the act about safety at sea.

Materials for lectures (likewise for classes), run in Institute of Navigation and Hydrography (INiHM) within confines of trainings for seamen, do meet requirements of the above said project of MTBiGM Decree at operational level in deck department. For officer trainees and civil students, algorithms for solving the problems (distinguished in the text by boxes with shades) are broadened by engineering issues, i.e. considering the Earth's sphericality and spheroidality.

The following elements of WGS-84 ellipsoid have been accepted in the proposed formulas and examples: $a=6378137,0 \mathrm{~m} ; \mathrm{b}=6356752,3142 \mathrm{~m} ; 1 / \mathrm{f}=$ 298,257 223 563, first eccentric e $=0.081819191$.

Formulas regarding the rhumbline sailing computation are given in a form convenient for calculations done with a use of commonly accessible electronic calculators. Therefore, there are records of trigonometric functions typical for calculators applied there, e.g. $\tan$ as $\operatorname{tg}, \sin ^{-1}$ as $\arcsin , \cos ^{-1}$ as $\arccos , \tan ^{-1}$ as $\operatorname{arctg}$ with no application of $c t g$, sec, cosec functions.

\section{Loxodrome Equation}

A vessel maintaining constant heading moves along loxodrome (rhumb line) which is a line cutting all the meridians at the same angle. The Earth's meridians are not parallel to each other, thus the line crossing them at the same angle is not a straight line but a logarithmic spiral - a line of double curvature, heading for the Earth's pole in asymptotic way (Woźnicki, 1954).

Segment (D) of the rhumb line crossing two points $\left(P_{1} P_{2}\right)$ on the Earth surface makes a hypotenuse of spheroidal right-angled triangle $\left(\mathrm{P}_{1} \mathrm{P}_{2} \mathrm{C}\right)$ - the so-called loxodromic triangle (fig. 1). Navigational departure $(\Delta \mathrm{l})$ is an east-west oriented leg of the said triangle and difference in latitude $(\Delta \varphi)$ is its meridional leg - expressed in nautical miles, calculated from the dependence (1) (Urbański et al.,1996):

$$
\begin{gathered}
\mathrm{CP}_{2}=\Delta \mathrm{I}=\left(\lambda_{2}-\lambda_{1}\right) \cdot \cos \varphi=\Delta \lambda \cdot \cos \varphi \\
\mathrm{CP}_{1}=\Delta \varphi=\varphi_{2}-\varphi_{1}
\end{gathered}
$$

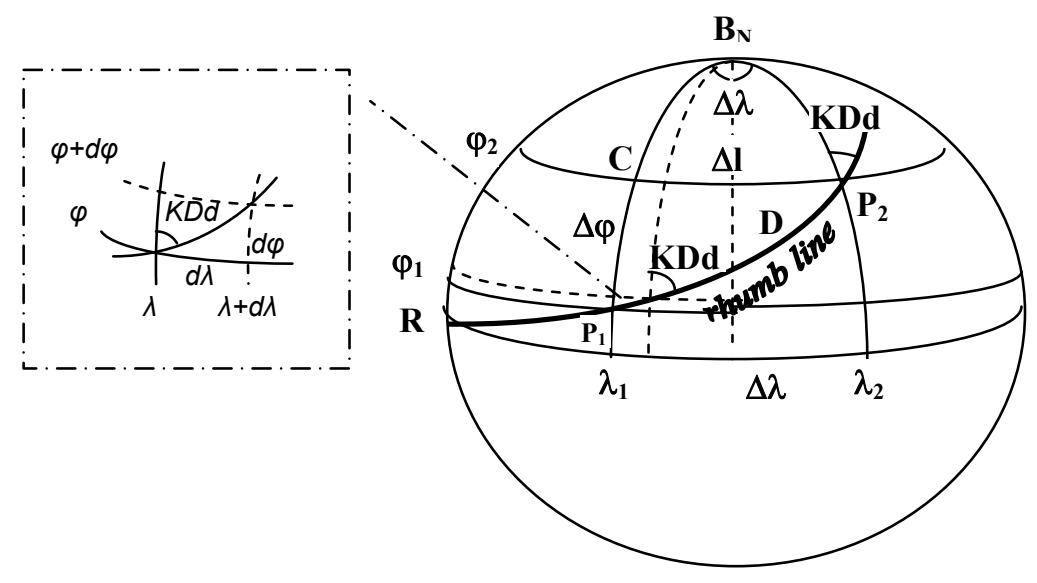

Fig. 1. Loxodromic triangle

Having in mind the dependence (1), it follows from a small loxodromic triangle $\mathrm{P}_{1} \mathrm{P}_{2} \mathrm{C}$, which may be accepted as a planar right-angled triangle, that: 


$$
\tan K D d=\frac{\Delta l}{\Delta \varphi}=\frac{\Delta \lambda \cdot \cos \varphi}{\Delta \varphi} \Rightarrow \Delta \lambda=\tan K D d \frac{\Delta \varphi}{\cos \varphi}
$$

Moving from small increments to infinitesimal ones

$$
\Delta \lambda \rightarrow d \lambda \quad \text { and } \Delta \varphi \rightarrow d \varphi
$$

results in obtaining differential equation - to integrate it within the range of changes of $\varphi$ and $\lambda$

$$
d \lambda=\tan K D d \frac{d \varphi}{\cos \varphi} \quad ; \quad \int_{\lambda_{1}}^{\lambda_{2}} d \lambda=\tan K D d \int_{\varphi_{1}}^{\varphi_{2}} \frac{d \varphi}{\cos \varphi}
$$

The integration follows to an equation (2) describing investigation of the rhumb line crossing two points on the Earth surface (Dimitrev et al., 2004):

$$
\lambda_{2}-\lambda_{1}=\tan K D d\left[\ln \tan \left(45^{\circ}+\frac{\varphi_{2}}{2}\right)-\ln \tan \left(45^{\circ}+\frac{\varphi_{1}}{2}\right)\right]
$$

The loxodrome equation on the ellipsoid (with the Earth oblateness taken into consideration) has the following form (3) (Urbański et al., 1996):

$$
\lambda_{2}-\lambda_{1}=\tan K D d\left[\ln \tan \left(45^{\circ}+\frac{\varphi_{2}}{2}\right)\left(\frac{1-e \cdot \sin \varphi_{2}}{1+e \cdot \cos \varphi_{2}}\right)^{\frac{e}{2}}-\ln \tan \left(45^{\circ}+\frac{\varphi_{1}}{2}\right)\left(\frac{1-e \cdot \sin \varphi_{1}}{1+e \cdot \cos \varphi_{1}}\right)^{\frac{e}{2}}\right]
$$

where:

$\varphi_{1}, \lambda_{1}$ - coordinates of rhumb line's $P_{1}$ starting point;

$\varphi_{2}, \lambda_{2}$ - coordinates of rhumb line's $P_{2}$ starting point;

$\mathrm{KDd}$ - path angle over sea bed (real loxodrome course);

e - first eccentric of Earth's ellipsoid.

Analysis of the loxodrome equation follows to the conclusion that:

a) the loxodrome crosses every meridian infinite number of times but each time at different latitude (a spiral),

b) when $\mathrm{KDd}=0^{\circ}\left(180^{\circ}\right)$, the loxodrome follows an Earth meridian,

c) when $\mathrm{KDd}=90^{\circ}\left(270^{\circ}\right)$, the loxodrome follows an Earth parallel,

d) and it follows equator at $\varphi_{2}=\varphi_{1}=0^{0}$.

Expressions of the equations (2) and (3) given in square brackets are differences of meridional parts (isometric latitudes) of points $P_{1}, P_{2}$ on the sphere and on the ellipsoid (in radians), namely:

$$
\Delta \mathrm{V}=\mathrm{V}_{2}-\mathrm{V}_{1}
$$

Formulas for calculating the meridional parts, in nautical miles have the following forms:

a) on the sphere (5) (Woźnicki, 1954):

$$
V_{k}=7915.70447 \cdot \lg \tan \left(45^{\circ}+\frac{\varphi}{2}\right)
$$

b) on the ellipsoid (6) (Urbański et al., 1996): 


$$
V_{e}=7915.70447 \cdot \lg \left(\tan \left(45^{\circ}+\frac{\varphi}{2}\right) \cdot\left(\frac{1-e \cdot \sin \varphi}{1+e \cdot \sin \varphi}\right)^{\frac{e}{2}}\right)
$$

c) on WGS84 (7) (Bowdith, 2002):

$$
V_{W G S 84}=3437,746771 \cdot \ln \tan \left(45^{\circ}+\frac{\varphi}{2}\right)-23,0135832 \sin \varphi-0,051353 \cdot \sin ^{3} \varphi
$$

Formulas for calculating difference of the meridional parts $(\Delta \mathrm{V})$ :

a) on the sphere $\left(\Delta V_{k}\right)$ :

$$
\Delta V_{k}=7915,70447^{\prime} \cdot \log \frac{\tan \left(45^{\circ}+\frac{\varphi_{2}}{2}\right)}{\tan \left(45^{\circ}+\frac{\varphi_{1}}{2}\right)}
$$

b) on the ellipsoid $\left(\Delta \mathrm{V}_{\mathrm{e}}\right)$ :

$$
\Delta V_{e}=7915.70447 \cdot \lg \left(\frac{\tan \left(45^{\circ}+\frac{\varphi_{2}}{2}\right) \cdot\left(\frac{1-e \cdot \sin \varphi_{2}}{1+e \cdot \sin \varphi_{2}}\right)^{\frac{e}{2}}}{\tan \left(45^{\circ}+\frac{\varphi_{1}}{2}\right) \cdot\left(\frac{1-e \cdot \sin \varphi_{1}}{1+e \cdot \sin \varphi_{1}}\right)^{\frac{e}{2}}}\right)
$$

where: $\quad 3437,746771=60 \frac{360^{\circ}}{2 \cdot \Pi}=60 \cdot 57.2957751$ $7915,70447=3437,746771 \cdot \ln 10$

The loxodrome equation (2) and (3), with (4) taken into consideration, obtains the following form (10):

$$
\lambda_{2}-\lambda_{1}=\tan K D d \cdot\left(V_{2}-V_{1}\right) \quad \text { or } \quad \Delta \lambda=\Delta V \cdot \tan K D d
$$

In navigation, problems regarding the mathematical totting are solved by means of:

- mean latitude - navigational triangle (mean latitude sailing),

- meridional parts - Mercator triangle (Mercator sailing).

\section{Mean and corrected mean latitude sailing (plane sailing)}

Small loxodromic triangle presented on a plane is called navigational triangle or plane sailing triangle.

The loxodromic and navigational triangles' elements are as the following (fig. 1 and 2):

$\Delta \mathrm{I}$ - navigational departure, (dep.)

$\Delta \varphi$ - difference of latitude (d.lat),

$\Delta \lambda$ - difference of longitude (d.long),

$\mathrm{D}$ - distance for the ship to go along the loxodrome,

$\mathrm{KDd}$ - course angle in respect to the sea bed (the course made good, with no wind and no current). 


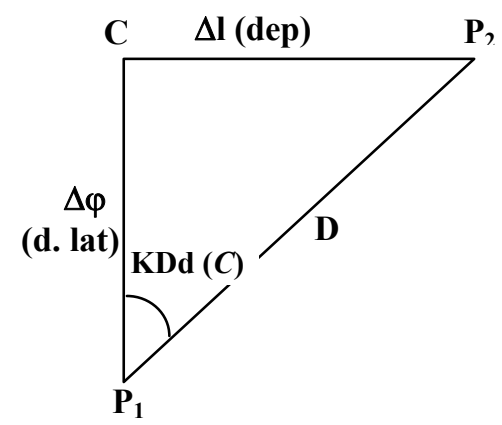

Fig. 2. Navigational triangle (plane sailing triangle)

The following dependencies result from the navigational (plane sailing) triangle:

$$
\Delta \varphi=D \cdot \cos K D d \quad \Delta l=D \cdot \sin K D d \quad K D d=\tan ^{-1} \frac{\Delta l}{\Delta \varphi}
$$

Solution of the problem requires recalculation of the longitude's $(\Delta \lambda)$ difference onto the navigational departure (and opposite). This task may be solved according to the mean navigational departure $\left(\Delta \mathrm{l}_{\text {śr }}\right)$, mean latitude $\left(\varphi_{\text {śr }}\right)$ and corrected (mathematical) mean latitude $\left(\varphi_{\text {śrm }}\right)$.

Example 1: Data

$\mathrm{A}: \varphi_{\mathrm{A}}=55^{0} \mathrm{~N}, \lambda_{\mathrm{A}}=010^{0} \mathrm{E}$

B: $\varphi_{B}=60^{\circ} \mathrm{N}, \lambda_{B}=015^{\circ} \mathrm{E}$ (Fig. 3)

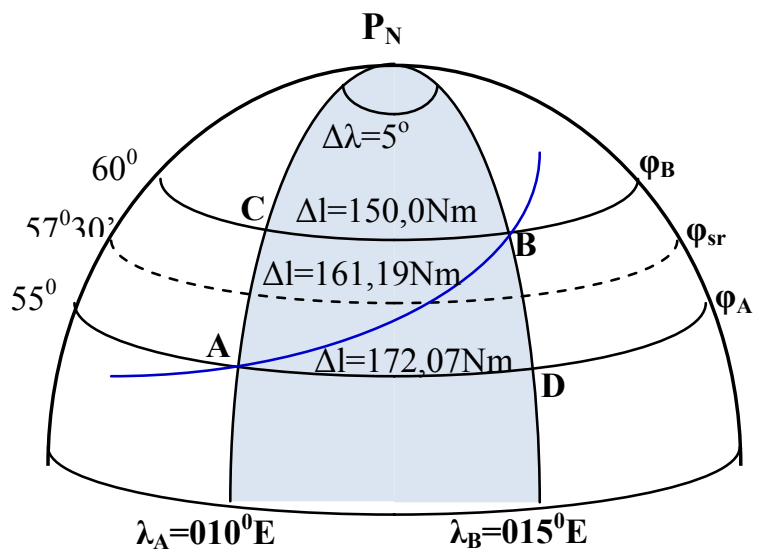

Fig. 3. Loxodromic triangle on a sphere - example

Solution:

$\Delta \lambda=\lambda_{B}-\lambda_{A}=015^{0}-010^{0}=5^{0} E=300^{\prime} E$

a). $\Delta l_{s r}$

$\Delta l_{A}=300 \cdot \cos 55^{\circ}=172,073 \mathrm{Nm} ; \quad \Delta l_{B}=300 \cdot \cos 60^{\circ}=150,0 \mathrm{Nm}$

$\Delta l_{s r}=\frac{\Delta l_{A}+\Delta l_{B}}{2}=\frac{172,073+150,0}{2}=\underline{161,037 \mathrm{Nm}}$

b). $\varphi_{s r}$

$$
\varphi_{s r}=\frac{55^{0}+60^{\circ}}{2}=57^{0} 30^{\prime} \quad \Delta l=300 \cdot \cos 57^{0} 30^{\prime}=\underline{161,190 \mathrm{Nm}}
$$


Small difference $161,190-161,037=0,153 \mathrm{Nm}$ (i.e. $~ 0,1 \%$ ) does confirm legitimacy for application of the mean latitude in calculations on a plane:

$$
\varphi_{\text {śr }}=\left(\varphi_{1}+\varphi_{2}\right) / 2
$$

c) accurate formula for mean latitude, the so-called corrected (mathematical) mean latitude $\varphi_{\text {śrm }}$ may be obtained from the dependencies (6) and (8), with the (7) taken into consideration, namely (Admiralty Manual of Navigation, 1998]) (13):

$$
\varphi_{\text {śrm }}=\cos ^{-1}(\Delta \mathrm{l} / \Delta \lambda)=\cos ^{-1}(\Delta \varphi / \Delta \mathrm{V}
$$

Application of the dependence (13) in the referred example results in:

$$
\begin{aligned}
\varphi_{\text {śrm }} & =\cos ^{-1}(\Delta \varphi / \Delta V)=\cos ^{-1}(300 / 559,40165)=57^{\circ} 34,125^{\prime} \\
\Delta \mathrm{I} & =\Delta \lambda \cdot \cos \varphi_{\text {śrm }}=300 \cos 57^{\circ} 34,125^{\prime}=160,886 \mathrm{Nm}
\end{aligned}
$$

The difference $160,886-161,190=-0,304$ (i.e. $\sim 0,2 \%$ ) also confirms possibility of applying the latitude $\left(\varphi_{\text {śr }}\right)$ in calculations on a plane, with a satisfactory accuracy in navigational practice. In order to achieve higher accuracy, one should take the spherical shape of the Earth into consideration, hence to apply the mean plane (mathematical) latitude ( $\left.\varphi_{\text {śrm }}\right)$

The above dependencies serve solving the first and the second problems of navigation along the loxodrome, i.e. the tasks of direct and inverse rhumb line sailing.

A. The first problem of loxodromic navigation - the direct RLS problem: calculating coordinates of the vessel's arrival position $P_{2}\left(\varphi_{2}, \lambda_{2}\right)$ based on known coordinates of her departure point $P_{1}\left(\varphi_{1}, \lambda_{1}\right)$, route angle over the sea bed (KDd) and the distance she has covered (D) - the direct RLS problem.

Algorithms of the problem solution - based on formulas of the plane sailing triangle:

a) acc. to the mean latitude $\left(\varphi_{\mathrm{sr}}\right)$

\begin{tabular}{|ll} 
1. & $\Delta \varphi=D \cdot \cos K D d$ \\
2. & $\varphi_{2}=\varphi_{1}+\Delta \varphi$ \\
3. & $\Delta l=D \cdot \sin K D d$ \\
4. & $\varphi_{s r}=\varphi_{1}+\frac{\Delta \varphi}{2}$ \\
5. & $\Delta \lambda=\frac{\Delta l}{\cos \varphi_{s r}}$ \\
6. & $\lambda_{2}=\lambda_{1}+\Delta \lambda$
\end{tabular}

b) acc. to the corrected (mathematical) mean latitude $\left(\varphi_{\text {srm }}\right)$

\begin{tabular}{|ll}
\hline 1. & $\Delta \varphi=D \cdot \cos K D d$ \\
2. & $\varphi_{2}=\varphi_{1}+\Delta \varphi$ \\
3. & $\Delta l=D \cdot \sin K D d$ \\
4. & $\Delta V_{k}=7915,7045^{\prime} \cdot \log \frac{\tan \left(45^{\circ}+\frac{\varphi_{2}}{2}\right)}{\tan \left(45^{\circ}+\frac{\varphi_{1}}{2}\right)}$ \\
5. & $\varphi_{s r m}=\cos ^{-1} \frac{\Delta \varphi}{\Delta V_{k}}$ \\
6. & $\Delta \lambda=\frac{\Delta l}{\cos \varphi_{s r m}}$ \\
7. & $\lambda_{2}=\lambda_{1}+\Delta \lambda$ \\
\hline
\end{tabular}

\section{Example 2:}

From a position $\mathrm{P}_{1}$ of coordinates $\varphi_{1}=57^{\circ} 23,35^{\prime} \mathrm{N}, \quad \lambda_{1}=020^{\circ} 14,18^{\prime} \mathrm{E}$, a vessel has covered a distance of $D=175,2$ nautical miles, along $K D d=227,5^{\circ}$ course. Calculate coordinates $\left(\varphi_{2}\right.$ and $\left.\lambda_{2}\right)$ of her arrival position $P_{2}$ by means of formulas of the plane sailing (navigational) triangle: 
Solution:

a) acc. to the mean latitude $\left(\varphi_{\mathrm{sr}}\right)$

$$
\varphi_{2}=55^{\circ} 24,99^{\prime} \mathrm{N}, \quad \lambda_{2}=016^{\circ} 20,75^{\prime} \mathrm{E}
$$

b) acc. to the corrected (mathematical) mean latitude $\left(\varphi_{\mathrm{sm}}\right)$

$$
\varphi_{2}=55^{\circ} 24,99^{\prime} \mathrm{N}, \quad \lambda_{2}=016^{\circ} 20,68^{\prime} \mathrm{E}
$$

B. The second problem of loxodromic navigation - inverse rhumb line sailing takes place when coordinates of the departure position $P_{1}\left(\varphi_{1}, \lambda_{1}\right)$ and of the arrival position $\mathrm{P}_{2}\left(\varphi_{2}, \lambda_{2}\right)$ are known, and the course $\mathrm{KR}(\mathrm{KDd})$ and the route $\mathrm{D}$ connecting the points should be calculated.

The following dependencies serve the above:

a) acc. to the mean latitude $\left(\varphi_{\mathrm{sr}}\right)$

\begin{tabular}{|ll|}
\hline 1. & $\Delta \varphi=\varphi_{2}-\varphi_{1}$ \\
2. & $\Delta \lambda=\lambda_{2}-\lambda_{1}$ \\
3. & $\varphi_{s r}=\frac{\varphi_{1}+\varphi_{2}}{2}$ \\
4. & $\Delta l=\Delta \lambda \cdot \cos \varphi_{s r}$ \\
5. & $K D d=\tan ^{-1} \frac{\Delta l}{\Delta \varphi}$ \\
6. & $D=\frac{\Delta \varphi}{\cos K D d}$ \\
& lub \\
& $D=\frac{\Delta l}{\sin K D d}$
\end{tabular}

b) acc. to the corrected (mathematical) mean latitude $\left(\varphi_{\text {srm }}\right)$

1. $\Delta \varphi=\varphi_{2}-\varphi_{1}$
2. $\Delta \lambda=\lambda_{2} \lambda_{1}$
3. $\Delta V_{k}=7915,7045 \log \frac{\tan \left(45^{\circ}+\frac{\varphi_{2}}{2}\right)}{\tan \left(45^{\circ}+\frac{\varphi_{1}}{2}\right)}$
4. $\quad \varphi_{s r m}=\cos ^{-1} \frac{\Delta \varphi}{\Delta V_{k}}$
5. $\Delta l=\Delta \lambda \cdot \cos \varphi_{s r m}$
6. $\quad K D d=\tan ^{-1} \frac{\Delta l}{\Delta \varphi}$
7. $D=\frac{\Delta \varphi}{\cos K D d}$

Example 3: From the position $\mathrm{P}_{1}$ of coordinates $\varphi_{1}=51^{\circ} 09,35^{\prime} \mathrm{N}, \lambda_{1}=010^{\circ} 05,30^{\prime} \mathrm{W}$, the vessel is to arrive at the position $P_{2}$ of coordinates $\varphi_{2}=49^{\circ} 14,85^{\prime} \mathrm{N}, \lambda_{2}=$ $006^{\circ} 12,06^{\prime} \mathrm{W}$. Calculate the course (KDd) and the loxodromic distance (D).

Solution:
a) acc. to the mean latitude $\left(\varphi_{\mathrm{sr}}\right)$
$\mathrm{KDd}=127,49^{\circ}, \mathrm{D}=188,15$ nautical miles
b) acc. to the corrected (mathematical) mean latitude $\left(\varphi_{\mathrm{sm}}\right)$
$\mathrm{KDd}=127,49^{\circ}, \mathrm{D}=188,13$ nautical miles

\section{Mercator sailing}

Formulas of the navigational triangle are applicable in practical navigation when:

- latitudes are small or average (Urbański et al., 1996), $\varphi<50^{\circ}$ (Dimitrev et al., 2004), $\varphi<60^{\circ}$ (Wolski, 2012);

- $\Delta \varphi<3^{\circ}-5^{\circ}$ (Urbański et al., 1996), $\Delta \varphi<5^{\circ}$ (Wolski, 2012);

- $\quad \mathrm{D}<300$ - 500 nautical miles (Urbański et al., 1996), D <600' (AMoN, 1998), $\mathrm{D}<$ "a few hundred nautical miles" (Bowdith, 2002), $\mathrm{D}<600$ nautical miles (Wolski, 2012). 
Should the above conditions be not met, the calculations done based on the navigational triangle's formulas shall be burdened with serious inaccuracies. Therefore, in practice, formulas of the Mercator triangle (Mercator sailing) are applied.

The Mercator triangle occurs as a result of the loxodromic triangle's surjection onto cylinder's side surface (Mercator projection) and it contains the following elements (fig. 4):

$\Delta \lambda$ - difference of longitude (d.long),

$\Delta \mathrm{V}$ - difference of meridional parts-(DMP)

$\mathrm{KDd}(\mathrm{KR})$ - vessel's course made good (CMG)

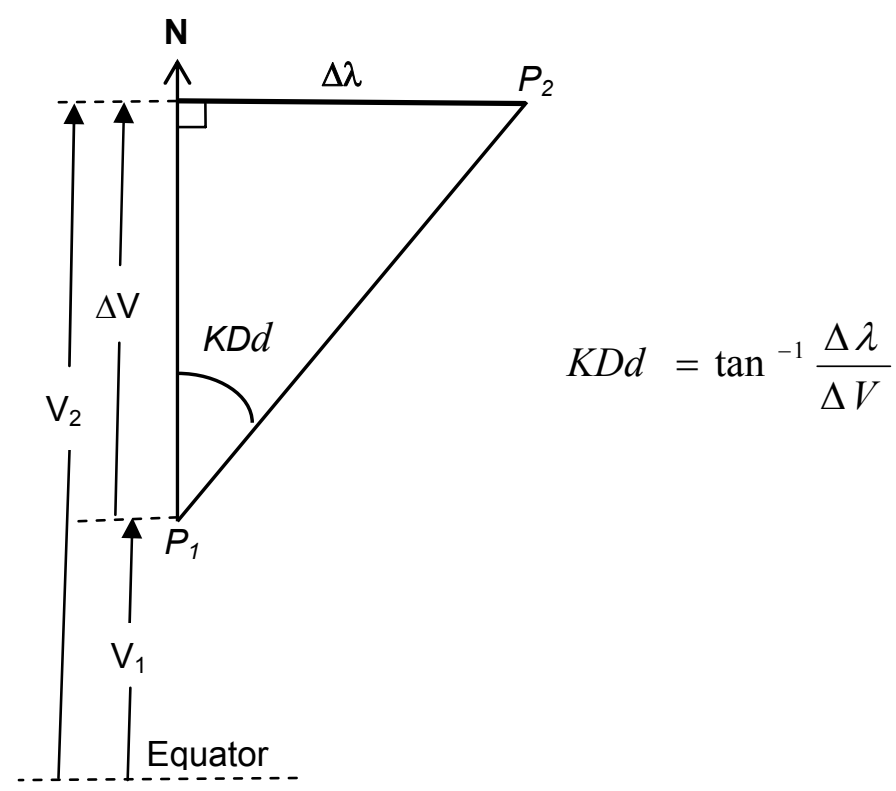

Fig. 4. Elements of navigational triangle (continuous lines) and of Mercator triangle (dashed lines)

\section{A. The first problem of loxodromic navigation - the direct RLS problem}

As a rule, solving the direct problem based on the Mercator triangle's formulas is executed with a use of the following algorithm of calculations:

$\begin{array}{ll}\text { 1. } & \Delta \varphi=D \cdot \cos K D d \\ \text { 2. } & \varphi_{2}=\varphi_{1}+\Delta \varphi \\ \text { 3. } & \Delta V_{k}=7915,7045 \log \frac{\tan \left(45^{\circ}+\frac{\varphi_{2}}{2}\right)}{\tan \left(45^{\circ}+\frac{\varphi_{1}}{2}\right)} \quad \text { (19) } \\ \text { 4. } & \Delta \lambda=\Delta V \cdot \operatorname{tg} K D d \\ \text { 5. } & \lambda_{2}=\lambda_{1}+\Delta \lambda\end{array}$


Solution of the problem executed based on the above algorithm does not take the ellipsoidal shape of the Earth into consideration (it is a solution made on a sphere) because:

- difference of latitude $(\Delta \varphi)$ is calculated with an assumption that length of the nautical mile is constant ( 1 nautical mile $=1^{\prime}=1852 \mathrm{~m}$ ),

- differences of meridional parts $(\Delta \mathrm{V})$ are calculated on a sphere - table 11 of Navigation tables (TN-89) contains values of the meridional parts (V) calculated for Krasovsky ellipsoid.

Therefore, accurate solution of the problem on ellipsoid requires:

a) calculation of the meridian arc's length on the ellipsoid $\left(S_{e}\right)$ and the length is expressed with the following formula (AMoN, 1998), (Weintrit \& Kopacz, 2012), (Woźnicki, 1954):

$$
\begin{aligned}
& S_{e}=\int_{\varphi_{1}}^{\varphi_{2}} M d \varphi=\int_{\varphi_{1}}^{\varphi_{2}} \frac{a\left(1-e^{2}\right)}{\left(1-e^{2} \cdot \sin ^{2} \varphi\right)^{\frac{3}{2}}} d \varphi \\
& S_{e}=A \cdot \Delta \varphi-B\left(\sin 2 \varphi_{2}-\sin 2 \varphi_{1}\right)+C\left(\sin 4 \varphi_{2}-\sin 4 \varphi_{1}\right)-D\left(\sin 6 \varphi_{2}-\sin 6 \varphi_{1}\right)+\ldots
\end{aligned}
$$

For the WGS-84, when calculating the length of the meridian arc starting with the equator $\left(\varphi_{1}=0, \varphi_{2}=\varphi\right)$, one can apply the following formula [6]:

$$
S_{(W G S 84)}=60,006994 \cdot \varphi^{o}-8,660102 \cdot \sin 2 \varphi[\mathrm{Nm}]
$$

b) calculation of the meridional parts according to the formulas $(6,7)$, and the difference of the meridional parts $(\Delta \mathrm{V})$ can be calculated, for example, from the following formula as been shown (Kaukoranta, 2006):

$$
\begin{gathered}
\Delta V_{W G S 84}=3437,7467708 \cdot \ln \left(\frac{\tan \left(\frac{\Pi}{4}+\frac{\varphi_{2}}{2}\right)}{\tan \left(\frac{\Pi}{4}+\frac{\varphi_{1}}{2}\right)}\right)-23,013583 \cdot\left(\sin \varphi_{2}-\sin \varphi_{1}\right)- \\
-0,051353 \cdot\left(\sin ^{3} \varphi_{2}-\sin ^{3} \varphi_{1}\right)-0,000206 \cdot\left(\sin ^{5} \varphi_{2}-\sin ^{5} \varphi_{1}\right)
\end{gathered}
$$

In addition, execution of the latitude calculation $\left(\varphi_{2}\right)$ - when solving the problem in direct way - requires application of the dependence (19) and the repeated distribution (usually -3 iterations). 
Taking into consideration the above, the algorithm (19) obtains the following form:

$$
\begin{array}{ll}
\text { 1. } & S_{(W G S 84)}=60,006994 \cdot \varphi^{o}-8,660102 \cdot \sin 2 \varphi \\
\text { 2. } & \Delta S(\Delta \varphi)=D \cdot \cos K D d \\
\text { 3. } & S_{2}=S_{1}+\Delta S \\
\text { 4. } & \varphi_{2} \quad \text { is calculated from formula (19) with iteration method applied } \\
& \text { for } \quad \varphi_{2(1)}=\frac{S_{2}}{60} ; \\
& S_{2(1)}=60,006994 \cdot \varphi_{2(1)}{ }^{o}-8,660102 \cdot \sin \left(2 \cdot \varphi_{2(1)}\right) \\
& \varphi_{2(2)}=\varphi_{2(1)}+\frac{S_{2}-S_{2(1)}}{60} \\
& S_{2(2)}=60,006994 \cdot \varphi_{2(2)}{ }^{o}-8,660102 \cdot \sin \left(2 \cdot \varphi_{2(2)}\right) \\
& \varphi_{2(3)}=\varphi_{2(2)}+\frac{S_{2}-S_{2(2)}}{60} \\
& S_{2(3)}=60,006994 \cdot \varphi_{2(3)}{ }^{\circ}-8,660102 \cdot \sin \left(2 \cdot \varphi_{2(3)}\right) \\
& \varphi_{2(4)}=\varphi_{2(3)}+\frac{S_{2}-S_{2(3)}}{60} \\
\text { 5. } & \varphi_{2}=\varphi_{2(4)} \\
& V_{(W B S 84)}=7915,704468 \cdot \lg \left[\tan \left(45^{\circ}+\frac{\varphi}{2}\right)\right]-23,01358 \cdot \sin \varphi-0,05135 \cdot(\sin \varphi)^{3} \\
\text { 6. } & \Delta V=V_{2}\left(\varphi=\varphi_{2}\right)-V_{1}\left(\varphi=\varphi_{1}\right) \\
\text { 7. } & \Delta \lambda=\Delta V \cdot \operatorname{tg} K D d \\
\text { 8. } & \lambda_{2}=\lambda_{1}+\Delta \lambda
\end{array}
$$

\section{Example 4:}

From position $\mathrm{P}_{1}$, of coordinates $\varphi_{1}=33^{\circ} 00^{\prime} \mathrm{S}, \lambda_{1}=122^{\circ} 40^{\prime} \mathrm{W}$ (Valparaiso, Chile), the vessel has covered a distance of $D=9100$ nautical miles, with a course $K D d=297^{\circ}$. Calculate coordinates $\varphi_{2}$ and $\lambda_{2}$ of the arrival position $\mathrm{P}_{2}$ :

Solution:

a) acc. to meridional parts on a sphere (algorithm 18)

$$
\varphi_{2}=35^{\circ} 51,31^{\prime} \mathrm{N}, \quad \lambda_{2}=093^{\circ} 10,69^{\prime} \mathrm{E}
$$

b) acc. to meridional parts with traditional method applied $(\Delta \varphi-$ on a sphere, while $\Delta \lambda$ - on the WGS-84 ellipsoid)

$$
\varphi_{2}=35^{\circ} 51,31^{\prime} \mathrm{N}, \quad \lambda_{2}=094^{\circ} 02,28^{\prime} \mathrm{E}
$$

c) acc. to meridional parts on the WGS-84 ellipsoid (algorithm 22)

$$
\varphi_{2}=36^{\circ} 06,99^{\prime} \mathrm{N}, \quad \lambda_{2}=093^{\circ} 24,43^{\prime} \mathrm{E}
$$

\section{B. The second problem of loxodromic navigation - inverse rhumb line sailing problem}

Algorithms of solution of the navigation second problem - based on dependencies of the Mercator triangle (Mercator sailing): 
a) with traditional method applied (D - on a sphere, KDd - on WGS-84)

$$
\begin{aligned}
& \text { 1. } \Delta \varphi=\varphi_{2}-\varphi_{1} \\
& 2 . \Delta \lambda=\lambda_{2}-\lambda_{1} \\
& 3 . \Delta V_{W G S 84}=V_{2}\left(\varphi_{2}\right)-V_{1}\left(\varphi_{1}\right) \\
& 4 . K D d=\tan ^{-1} \frac{\Delta \lambda}{\Delta V_{W G S 84}} \\
& 5 . D=\frac{\Delta \varphi}{\cos K D d}
\end{aligned}
$$

\section{Example 5:}

From position $\mathrm{P}_{1}$ of coordinates $\varphi_{1}=29^{\circ} 51^{\prime} \mathrm{S}, \lambda_{1}=031^{\circ} 04^{\prime} \mathrm{E}$, the vessel has arrived at the position $\mathrm{P}_{2}$ of coordinates $\varphi_{2}=06^{\circ} 30^{\prime} \mathrm{S}, \lambda_{2}=105^{\circ} 00^{\prime} \mathrm{E}$. Calculate the course $(\mathrm{KDd})$ and the covered distance (D).

Solution:

a) with traditional method applied (algorithm 23):

$\mathrm{KDd}=71,57^{\circ}, \mathrm{D}=4431,35$ nautical miles,

b) with accurate method applied on the ellipsoid WGS-84 (algorithm 24):

$\mathrm{KDd}=71,57^{\circ}, \mathrm{D}=4414,38$ nautical miles

It is clear from the above that differences between the traditional solution and the proposed solution with the accurate algorithm are significant. The differences are given on the below graphs (fig. 5 and 6); they show differences of the loxodromic distances calculated with the traditional algorithm used and with the accurate algorithm - depending on the starting and ending positions of the vessel (Tijardović, 2000).

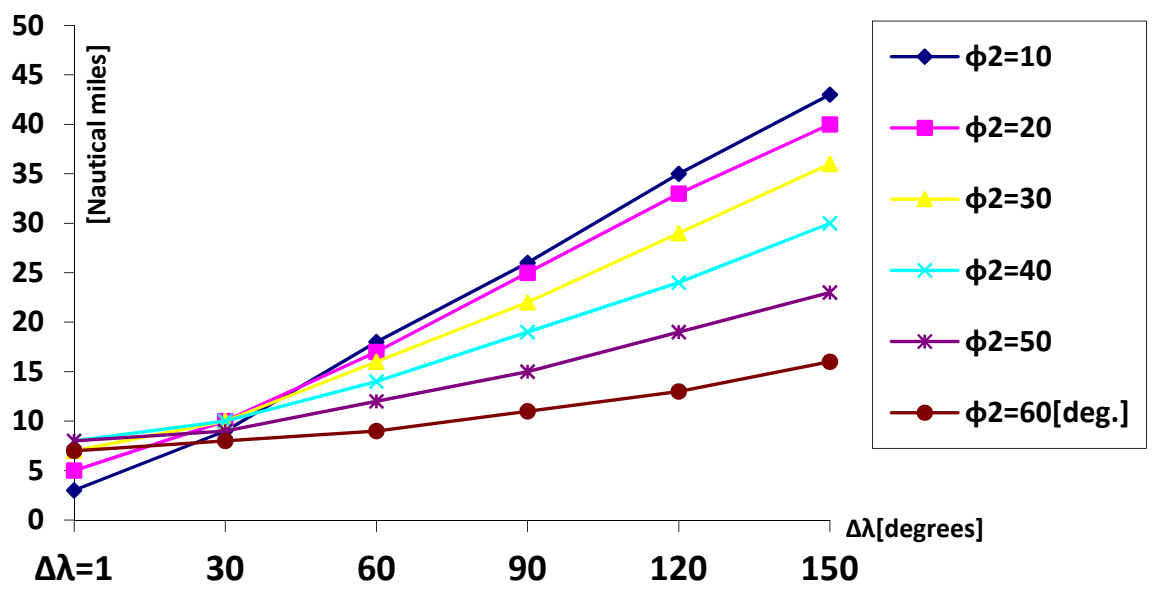

Fig. 5. Differences of loxodromic distances calculated with traditional algorithm used and with accurate logarithm - for latitude of starting position $\varphi_{1}=0^{\circ}$ 


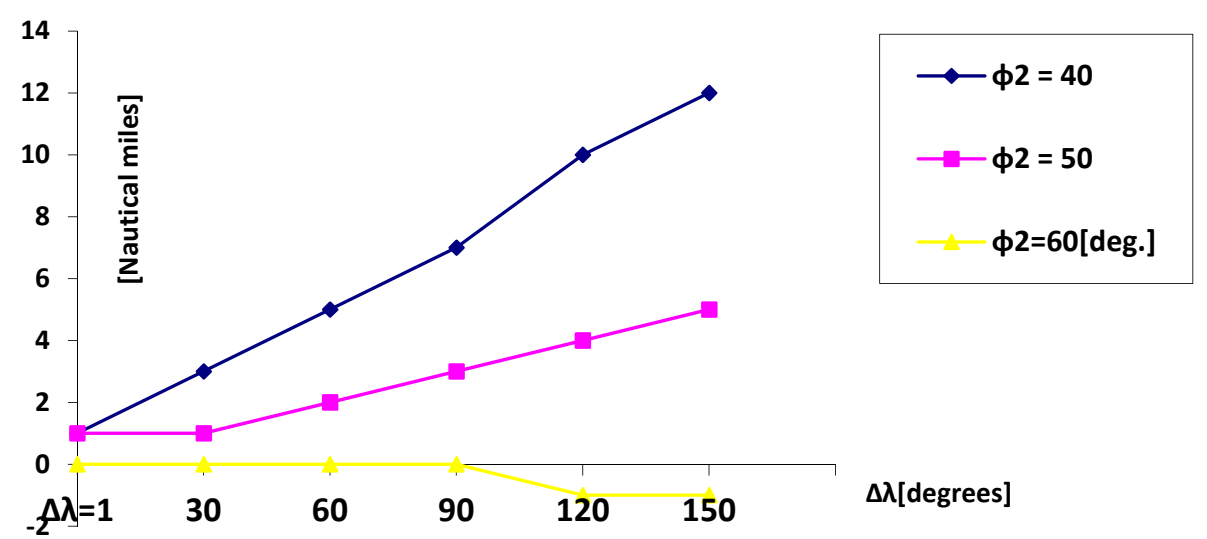

Fig. 6. Differences of loxodromic distances calculated with traditional algorithm used and with accurate logarithm - for latitude of starting position $\varphi_{1}=30^{\circ}$

It comes out from the graphs that difference of the loxodrome lengths:

- grows along with increase of $\Delta \lambda$ (which is obvious) and it reaches considerable value of over 40 nautical miles for $\Delta \lambda=150^{\circ}$ and $\varphi_{\text {śr }}=10^{\circ}$;

- decreases and it goes down to the minimum in average latitudes in the order of $\varphi_{\mathrm{sr}}=45^{\circ}$.

\section{Conclusions}

Solving problems of loxodromic (rhumb line) sailing in traditional navigation consists in application of simplified algorithms, according to mean latitude (plane triangle) and to meridional parts (Mercator triangle).

For the engineering needs, accurate calculations require application of algorithms that take sphericality and spheroidality of the Earth into consideration.

In the paper, the authors have presented proposals for both simplified and accurate solutions that meet contemporary requirements in respect to accuracy of navigation conduction.

\section{References}

Admiralty Manual of Navigation. (AMoN) Vol. I, Revised 1987, (1998). London: Ministry of Defence, Directorate of Naval Warfare.

Bowdith, N., (2002). The American Practical Navigator. (Bicentennial Edition). USA: NIMA, Bethesda, Maryland.

Dimitrev, V. I., Grigorân, V. L. \& Katenin, V.A., (2004): Navigaciâ i lociâ. Moskwa: IKC «Akademkniga».

Kaukoranta, J., (2006). Loxodrome (Mercator) course and distance on the WGS ellipsoid. Retrieved from http://kotisivu.mbnet.fi/jukaukor.

Minister Transportu, Budownictwa i Gospodarki Morskiej (MTGM), (2013). Projekt Rozporządzenia z dnia 28 lutego 2013 r. w sprawie programów szkoleń $i$ wymagań egzaminacyjnych dla marynarzy działu pokładowego. Retrieved from 


\section{http://bip.transport.gov.pl/pl/bip/projekty aktow prawnych/}

Pallikaris, A., Tsoulos, L. \& Paradissis D., (2009). New Meridian Arc formulas for Calculations in navigational GIS. International Hydrographic Review, May 2009, pp. 24-34.

Tijardović, I., (2000). Rhumbline Distances. The Journal of Navigation, vol. 53(1), pp. 187-191.

Urbański, J., Kopacz, Z. \& Posiła, J., (1996). Nawigacja Morska, Część I i II, Gdynia: Akademia Marynarki Wojennej.

Weintrit, A. \& Kopacz, O., (2012). On computational algorithms implemented in Marine navigational software used in Marine navigation electronic devices and systems. Annual of Navigation, 19/2012, part 2, pp. 171-184.

Wolski, A., (2012) Loksodroma i ortodroma w nawigacji morskiej. Szczecin: Inżynieria.

Woźnicki, J., (1954). Loksodroma i ortodroma przy budowie siatki map nawigacyjnych. Warszawa: Wydawnictwa Komunikacyjne.

\section{Authors:}

Wacław Morgaś ${ }^{1}$, w.morgas@awm.gdynia.pl

Zdzisław Kopacz ${ }^{1}$, z.kopacz@amw.gdynia.pl

1) Polish Naval Academy,

ul. Śmidowicza 69

81-103 Gdynia 